\title{
PRELIMINARY DESIGN OF DECISION SUPPORT SYSTEM FOR CHINESE SEADIKE SAFETY MANAGEMENT
}

\author{
Zuo Qihua, Zhou Zhengping, Wang Chi, Sun Feng, Wang Hongchuan
}

\begin{abstract}
A Decision Support System for Chinese Seadike Safety Management (DSS-CSSM) based on Geographic Information System (GIS) and database technology is initially proposed and designed in this paper. DSS-CSSM contains three major parts, which are fundamental information database, risk analysis module and hazard assessment module. Kinds of numerical and physical model methods can be selected and used in the modules. With integration of the fundamental information, analysis models and appropriate Human Computer Interaction(HCI), DSS-CSSM can be used to help people evaluate hazard losses of Chinese seadike and make some effective decisions.
\end{abstract}

keywords: seadike safety ; decision support system; database; risk analysis; hazard assessment

\section{INTRODUCTION}

China is a great maritime country with a coastline of more than $18,000 \mathrm{~km}$. However, some natural disasters, such as storm surges and typhoons, have great influence on coastal population and economics safety. The State Oceanic Administration of China reported that storm surges struck Chinese coastal areas for 98 times during the past 10 years, and more than half of those storm surges also brought with other disasters. The mean annual disaster frequency of these past 10 years is much higher than that in the past decades(State of Oceanic Administration,2010). But the economy grows very rapidly in some coastal areas, local governments have paid more emphasis on protecting the safety protection. Some forecast and warning systems have been built up in the southeast coastal areas, such as Guangdong, Fujian and Zhejiang Provinces where storm surge disasters occur more frequently. But the protection situation is not very well in some underdeveloped coastal areas, and there isn't a united management system to handle the whole coastal areas in China till now. Meanwhile nature disaster assessments are usually made after storm surge attacks, so it's difficult to make an efficient and real-time protection to decrease disasters. It is essential to set up a reliable information system to support seadike management decision(Zhou Z. P., Zuo Q. H.,2011). In this paper, a Decision Support System for Chinese Seadike Safety Management (DSS-CSSM) based on Geographic Information System (GIS) and database technology is initially proposed and designed. With such kind of system, people can simulate various scenarios with different considerations, then evaluate seadike security situation and make reasonable decisions for coast protection in China.

\section{SYSTEM FRAMEWORK}

The general structure of DSS-CSSM contains three parts: fundamental information database, risk analysis module and hazard assessment module. The fundamental information database includes the data related to general seadike conditions, hydrometeorology, seadike structures, geologic hazards and the social economic conditions of protection areas. With this shared database, users can obtain the desired information as start points for further evaluation and analysis. The key part of DSS-CSSM is risk analysis module which incorporates four basic models that are storm surge, typhoon waves, nearshore wave propagation and seadike structure stability analysis. The hazard assessment module evaluates the impact of waves and storm surge, and seadike safety. It will calculate the inundation area, predict the economic loss. And more important, professional judgments, different maintenance 
managements and some real-time protection suggestions will be implemented. The logical relationship of modules in DSS-CSSM is shown in Fig. 1.

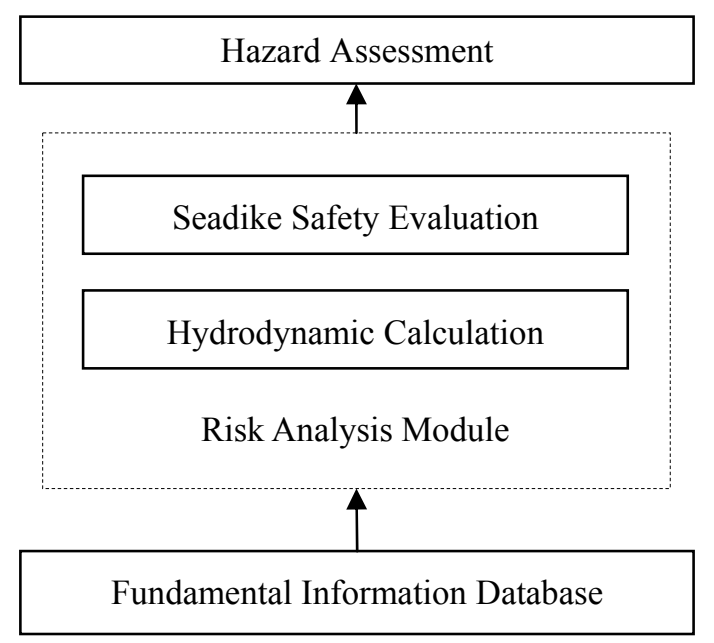

Figure 1. Modules logical relationship.

\section{FUNDAMENTAL INFORMATION DATABASE}

There is about $13,000 \mathrm{~km}$ seadike built to protect nearly 70 million people and 50 million hectares of arable land along Chinese shoreline. Because natural conditions and economy development are not the same in different coastal regions, the design standards for seadikes are also different from each other. But as the government devoting itself to strengthen seadike construction quality, most of the seadikes have reached the local design standards. Besides, the management of coastal oceanographic stations have also been paid much attention, the total number of coastal meteorological station has reached to more than 60 , and some of them have been built for 50 years.

By collecting and classifying the fundamental information of seadikes, such as general situation, seadike structure, hydrometeorology and natural disasters, the fundamental information database is set up. So far, kinds of information, including (1) offshore and nearshore topography in the Yellow, East, South and Bohai Seas with different grids; (2) measured wind and wave data from some typical coastal oceanographic stations; (3)seadike structural information, which are described by thousands of elements in DSS-CSSM; (4) historical data of storm surges and typhoons, such as atmospheric pressure, typhoon route, landing position and so on; (5) earthquake strength and its acceleration standards for seadike design. Most information has been obtained, cataloged and displayed for the system. Fig. 2 and Fig. 3 show the sketch of the topography and typical wind and wave data respectively.

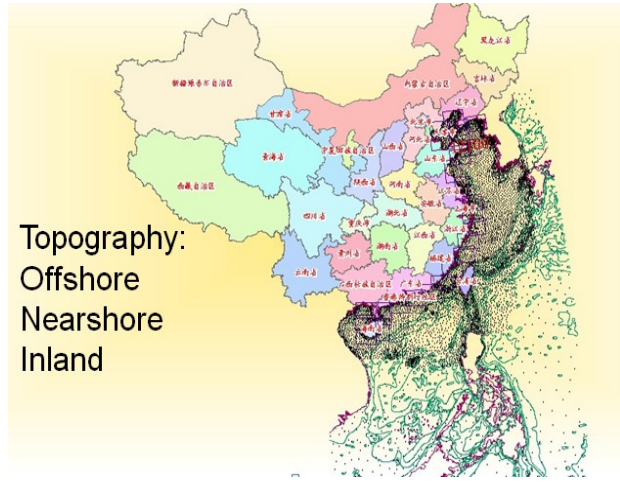

Figure 2. Sketch of the topography.

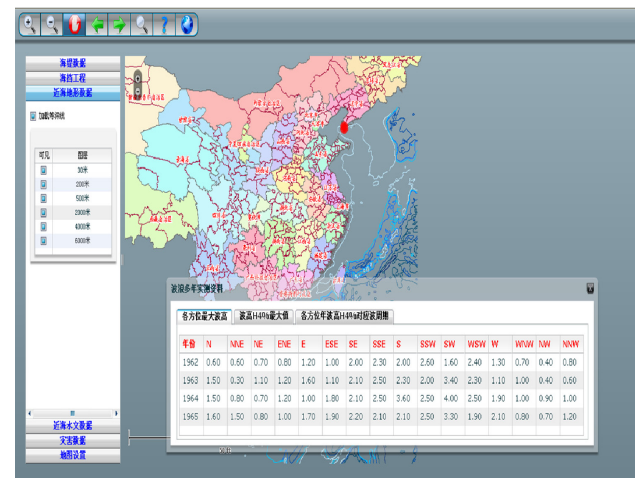

Figure 3. Typical wind and wave data. 


\section{RISK ANALYSIS MODULE}

Risk analysis module incorporates hydrodynamic calculation models and seadike safety evaluation models. Hydrodynamic calculation models contains three basic kinds of models: storm surge model, typhoon wave model, nearshore wave propagation model. And three methods can be applied to evaluate seadike safety situation.

The governing equations of the storm surge model are as follows(Zhang J. S., 2011):

$$
\begin{aligned}
& \frac{\partial \zeta}{\partial t}+\frac{\partial(h+\zeta) u}{\partial x}+\frac{\partial(h+\zeta) v}{\partial y}=0 \\
& \frac{\partial \mathrm{u}}{\partial t}+u \frac{\partial u}{\partial x}+v \frac{\partial u}{\partial y}-f v=-g \frac{\partial \zeta}{\partial x}-\frac{1}{\rho} \frac{\partial p}{\partial x}+\frac{\tau_{s x}-\tau_{b x}}{\rho(h+\zeta)}+\mathrm{D}_{\mathrm{x}} \Delta U \\
& \frac{\partial \mathrm{v}}{\partial t}+u \frac{\partial v}{\partial x}+v \frac{\partial v}{\partial y}+f u=-g \frac{\partial \zeta}{\partial \mathrm{y}}-\frac{1}{\rho} \frac{\partial p}{\partial y}+\frac{\tau_{s y}-\tau_{b y}}{\rho(h+\zeta)}+D_{y} \Delta V
\end{aligned}
$$

In which, $\mathrm{u}$ and $\mathrm{v}$ are horizontal velocity along depth-averaged component; $\mathrm{h}$ is water depth; $\zeta$ is

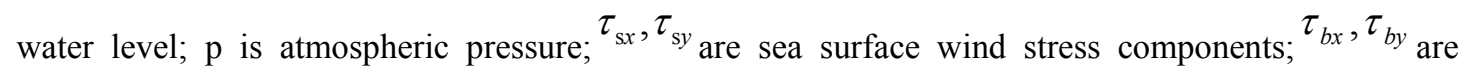
bottom friction stress components; $\mathrm{f}$ is the Coriolis force parameter.

The storm surge model solves the coupled two-dimensional astronomical tide with storm surge formulas by body-fitted coordinates (BFC)and improved ADI method. Besides, wind field is calculated by mesoscale meteorological model and triple nested computational grids are generated for deep sea, offshore and nearshore areas separately. Hindcasting method is applied to test and verify the air-flowing field and sea level data from typical coastal meteorological stations. Typhoon track, landing time and location, maximum wind speed and even water set-up can be predicted by analyzing of real-time meteorological maps and typhoon observation information in this model.

The typhoon wave model includes 2 parts which are wind wave and its surge. The governing equation for wind wave is(Wen S. C., Zhang D. C., 1989):

$$
\frac{\partial E}{\partial t}+\bar{V} \cdot\left[\left(\vec{C}_{g}+\vec{U}\right) E\right]+\frac{\partial}{\partial \theta}\left\{\left[\left(\vec{C}_{g}+\vec{U}\right) \cdot \bar{V} \theta\right] E\right\}+\frac{1}{2} S_{i j}\left(\frac{\partial U_{i}}{\partial x_{j}}+\frac{\partial U_{j}}{\partial x_{i}}\right)=S_{w}
$$

Where E is significant wave energy of unit vertical water column section; $\vec{C}_{g}$ is wave group velocity; $\vec{U}$ is flow velocity; $S_{i j}$ is radiation stress energy; $S_{w}$ is increase (or dissipation) rate of unit water column energy caused by several factors, such as wind stress input energy, flow influence on wave propagation, wave refraction, wave-wave interaction and wave breaking.

Surge is calculated by spectral component energy balance equation, which can be written as follows(Wen S. C., Zhang D. C., 1989; Pan J. N.,2007):

$$
\left.\frac{\partial F}{\partial t}+\bar{V} \cdot\left[\left(\vec{C}_{g}+\vec{U}\right) F\right]+\frac{\partial}{\partial \theta}\left\{\left(\vec{C}_{g}+\vec{U}\right) \cdot \bar{V} \theta\right] F\right\}+\frac{1}{2} S_{i j}\left(\frac{\partial U_{i}}{\partial x_{j}}+\frac{\partial U_{j}}{\partial x_{i}}\right)=S_{s}
$$

Where $\mathrm{F}$ is the directional spectrum, $\mathrm{S}(\omega)$ is wind wave frequency spectrum, $\vec{C}_{g}$ is wave group velocity, $S_{s}$ is source function, which contains wind effect term $s_{\text {in }}$ and bottom friction term $s_{\text {ab }}$.

Wind effect follows Snyder(Snyder R. L., F. W. Dobson, 1981), 


$$
S_{i n}=3 \times 10^{-4} \omega \frac{V \cos (\varphi-\psi)}{C} F(\omega, \theta)
$$

Where $\mathrm{V}$ is the wind speed at $10 \mathrm{~m}$ height over the sea surface, $\varphi_{\text {is composition wave direction; }}$ $\psi$ is wind direction; and $\theta=\varphi-\psi$. Bottom friction term follows Collins(Collins, J. I. , 1972),

$$
S_{d b}=-\frac{f g k^{2}\left|\bar{C}_{g}+\vec{U}\right|<u>}{(\omega c h k d)^{2}}
$$

In general, with real-time typhoon information, such as atmospheric pressure distribution, center position, radius of maximum wind velocity and typhoon root, the wave model predicts significant wave height, wave length, and its propagation direction in the offshore regions. Combined with water level setup obtained from the storm surge model, the wave model will also be verified by the measured data along the Chinese coasts. Wind wave can be computed in different return periods by comparison of the real-time and historical typhoon information. What's more, SWAN model can also be linked to simulate typhoon wave in the system.

In nearshore areas, especially in front of seadikes, complex topography affects shallow wave characteristics. Higher order nonlinearity parabolic type mild-slop equations (Wang H. C.,2007) are applied to simulate irregular wave refraction, diffraction and reflection by utilization of the results computed from the typhoon wave model as initial waves at deep water boundary. Then incident waves acting on seadikes may be obtained. Of course, the software, BW module of MIKE21, could also be linked to simulate nearshore wave propagation in the system.

5 different failure modes of seadikes are considered under wave and storm surge actions, including excessive wave overtopping, armor block failure, seadike toe local scour, parapet wall overturning and total structure slide. And There are three methods to evaluate seadike failure possibility. The simplest way is to compare real-time water level and waves caused by storm and storm surges with seadike design standards. If the indexes exceed the design standards, the seadikes might be unsafe. The second way is to calculate load forces according to "Code of Hydrology for Sea Harbor"(The Ministry of Transport,1998) and "Code for Design of Sea Dike Project”(The Ministry of Water Resources,2008), which assume the relation between distribution of structure resistance force $\mathrm{R}$ and hydrodynamic impact forces $\mathrm{S}$ is random and linear. Function of structure stability $\mathrm{Z}$ is expressed as:

$$
\mathrm{Z}=\mathrm{g}(\mathrm{R}, \mathrm{S})=\mathrm{R}-\mathrm{S}
$$

Performance function for failure probability is expressed as:

$$
P_{f}=P(Z<0)
$$

If both $\mathrm{R}$ and $\mathrm{S}$ follow normal distribution, function of structure reliability index $\beta$ can be expressed by the mean value and standard deviation of $Z$,

$$
\beta=\frac{\mu_{\mathrm{z}}}{\sigma_{z}}=\frac{\mu_{R}-\mu_{S}}{\sqrt{\sigma_{R}^{2}+\sigma_{S}^{2}}}
$$

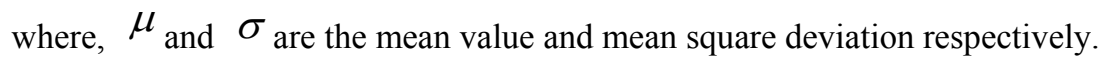

The third way is to use Monte-Carlo Method to evaluate seadike stability when the relation between distribution of $\mathrm{R}$ and $\mathrm{S}$ is nonlinear. Unbiased estimation of structure failure probability can be calculated according to the Law of Large Numbers. 
In general, the relationship of above-mentioned models is shown in Fig. 4.

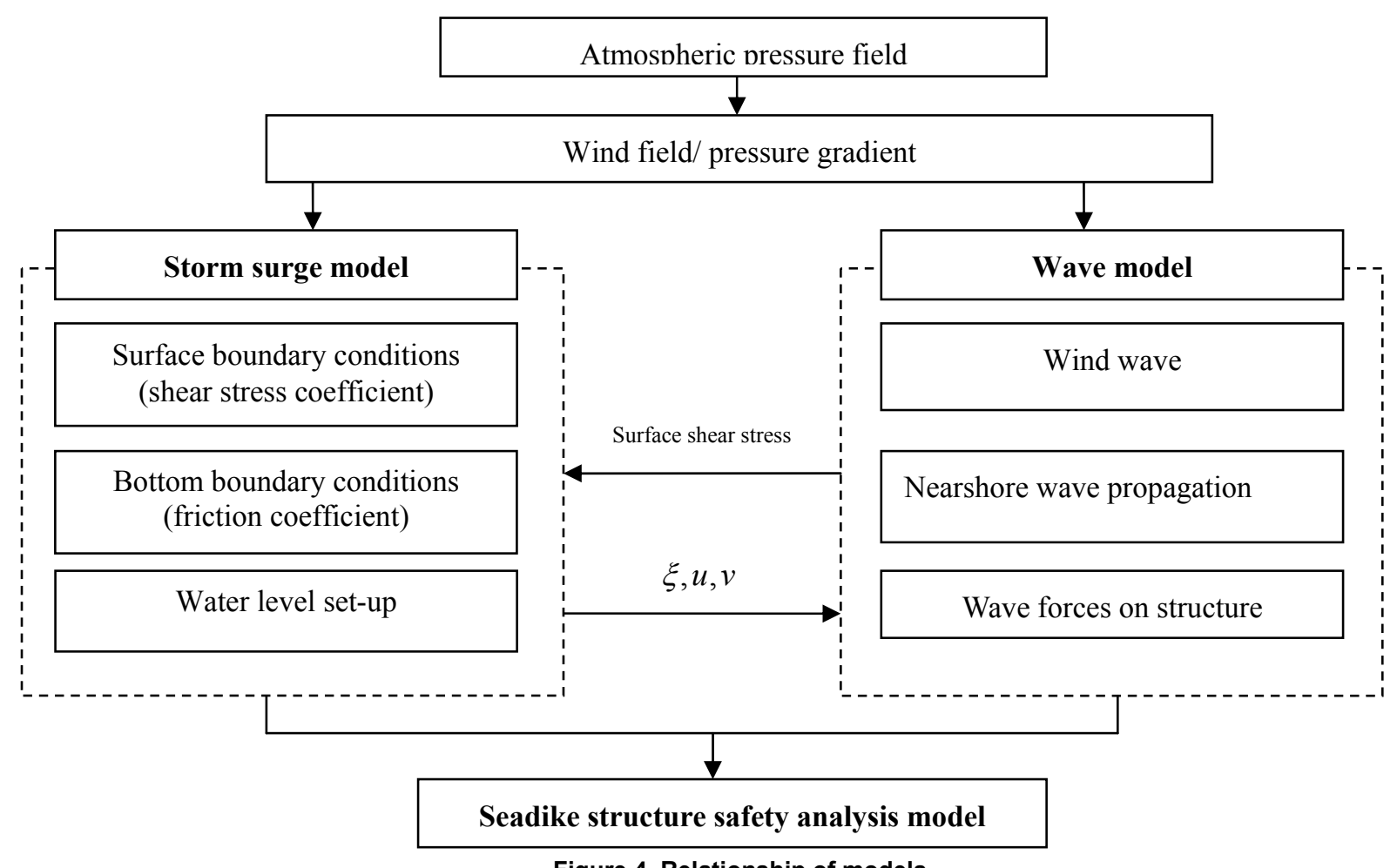

Figure 4. Relationship of models.

\section{HAZARD ASSESSMENT}

Hazard assessment of seadike failure is related to water overtopping volume, breach size, flood evolution, population, property, and so on in the protection zone. Because of uncertainty, DSS-CSSM initially proposes some hazard assessment methods to address this issue.

If there is no breach on seadike, wave overtopping is a main cause for flood hazards. With plenty of physical model data from the fundamental information database, a developed average water overtopping formula for Chinese seadikes is expressed as(Zhou Y. R. and Chen G. P. ,2006),

$$
\frac{Q}{\sqrt{g H_{s}^{3}}}=0.025 \gamma_{b 1} \gamma_{f} \xi \exp \left(-4 \frac{H_{c}}{\xi H_{s}}-0.6 \frac{P}{H_{c}}\right)
$$

Where, $\mathrm{Q}$ is average water overtopping volume.

If seadike fails, water overtopping volume is related to breach size, wave parameters and water level set-up. So a series of physical models in a wave basin will be taken up. After water flux and initial water level near breaches are given, 2D shallow wave propagation models, such as those in MIKE21, will be applied to simulate flood evolution. Generally, there are rivers for flood control and waterlog drainage behind seadikes in some underdeveloped regions of China. 1D unsteady flow river network model will be used firstly.

With the combination of disaster information with social-economic, geographic and historical disaster information, risk probability will be identified, damages caused by storm surges and typhoon waves will be figured out, and hazard assessment can be made. What's more, some measures to avoid, transfer and eliminate disasters in time will be studied. For example, the warning level should be adjusted as typhoon intensity, influence area, landing location change during a disaster process. 


\section{TECHNICAL DESIGN}

GIS is taken as a development platform and SQL Server relational database as a work platform in this study to build up DSS-CSSM, which can collect, modify and store spatial and temporal data as well as special events. DSS-CSSM has two important characteristics. The first one is the database management characteristic of GIS, and the other one is the attribute data model creation management functions of decision support system. Data input, output and application of modules can be finished by programming and its own operation. The integrated system of Flex plug-in is used to input and output pictures, sounds, videos, vector diagrams and other materials that are saved as digital information. And these kinds of digital information are stored separately to ensure DSS-CSSM can be modified quickly. In the process of DSS-CSSM set-up, further development has been taken into account. For example, data output from other commercial software can be easily used by setting up a data interface in this system. DSS-CSSM can be operated in a friendly HCI formation. With the comprehensive understanding of fundamental data, model characteristics and professional knowledge, decision makers can set up risk analysis schemes by using different resources. Analysis tools following HCI menu options can be applied to obtain desired information and make reasonable decisions. The main patterns of HCI include menu interaction, quiz interaction, imperative interaction and input or output form interaction, etc. Furthermore, HCI module incorporates six subsystems of input interpretation, input-processing, output-processing, charts generation, conversation controller and screen editor. Specifically, the input interpretation subsystem analyzes input information; the input-processing subsystem selects suitable operations according to results from the input interpretation; the output-processing subsystem executes operations from the previous subsystems' information; the chart generation subsystem has the function of generating relative charts; the conversation controller and screen editor allow the HCI system to output right information and charts.

\section{CONCLUSION}

In this research, a unified management system of DSS-CMSS includes database, GIS and decision support system is proposed. All the topography along the Chinese offshore and coastal areas, fifty-year typhoon, wind and wave records from many coastal meteorological stations, basic information of main seadikes, cross-dike constructions and earthquakes have been integrated into the system. Several numerical models, such as storm surges, typhoon waves and nearshore wave propagation, have been constructed and well verified. Methods for hazard assessment also have been implemented and carefully tested. DSS-CMSS may be used as a warning system for a real-time typhoon simulation and evaluation of hazards afterwards and also serves as an efficient tool for seadike management practice. In the future, more efforts will be put into the improvement of system reliability.

\section{ACKNOWLEDGMENTS}

Authors are grateful to the research foundation for "China Seadike Safety Risk Zoning and Storm Surge Envelope Diagram "(No. 200101061) provided by the Ministry of Water Resources, China.

\section{REFERENCES}

Collins, J. I. 1972. Prediction of Shallow Water Spectra. J. Geophys. Res. ,77, 2693- 2707.

Pan J. N. 2007. Numerical Simulation of Irregular Wave Propagation and Deformation. PhD. dissertation, Hohai University, China.

Snyder R. L., F. W. Dobson, et al. 1981. Array Measurements of Atmospheric Pressure Fluctuations Above Gravity Waves. J. Fluid Mech., 102, 1-59. 
State of Ooceanic Administration, the People's Republic of China. 2010. China Marine Disasters Gazettes from 2001 to 2010.

The Ministry of Transport, the People's Republic of China. 1998. Code of Hydrology for Sea Harbor.

The Ministry of Water Resources, the People's Republic of China. 2008. Code for Design of Sea Dike Project.

Wang H. C. 2007. Modification and Application of Mild Slop Equation. PhD. dissertation, Hohai University, China.

Wen S. C., Zhang D. C., et al. 1989. A Hybrid Model for Numerical Wave Forecasting and Its Implementation: Part I. Wind Wave Model. Acta Oceanologica Sinica, 8(1), 1-14.

Zhang J. S., et al(2011), Study of Impacts of Coastal Engineering on High Water Level Induced by Storm Surges in Bohai Bay. Applied Mechanics and Materials, 94-96, 810-814.

Zhou Y. R. and Chen G. P.(2006): Study of Storm Surge Disaster and Mitigation Measures Along Coastal Areas. Report, Nanjing Hydraulic Research Institute.

Zhou Z. P., Zuo Q. H., et al (2011): Preliminary Design of Support Systern for Seawall Safety Management[c]. Proceedings of APAC2011, Hongkong, China. 